\section{The effect of flap thickness on the visual and refractive outcome of myopic laser in situ keratomileusis}

Clínica Baviera, Instituto Oftalmológico Europeo, Grant Via Marques de Turia, Valencia, Spain

Correspondence: H Eleftheriadis, Department of Ophthalmology, Southend Hospital NHS Trust, Prittlewell Chase, Westcliff-on-Sea, Essex SSO ORY, UK Tel: + 441702 435555; Fax: + 441702221279 E-mail: h.eleftheriadis@ btinternet.com

Received: 29 May 2004 Accepted: 20 October 2004 Published online:

24 December 2004

Statement: None of the authors have any proprietary or financial interest in any of the products mentioned in this manuscript

Research funding: None

\begin{abstract}
Aims To study the effect of flap thickness on the visual and refractive outcome of myopic laser in situ keratomileusis (LASIK) surgery. Methods A total of 196 myopic eyes with spherical equivalent (SE) from -2.00 to -5.00 dioptres which underwent LASIK were studied retrospectively. Uncorrected visual acuity (UCVA), best-corrected visual acuity (BCVA) and manifest refraction were measured up to 6 months postoperatively. Logistic and linear regression analyses were used to examine the correlation of flap thickness to visual and refractive outcomes, postoperative complications and enhancement rate.
\end{abstract}

Results UCVA at 1 week and 1 month, but not at 1 day and at 6 months $(P>0.05)$, were negatively correlated to flap thickness $(P<0.05)$. BCVA was unrelated to flap thickness $(P>0.05)$. At 1-month post-LASIK sphere and cylinder were not related to flap thickness $(P>0.05)$, but spherical equivalent was negatively correlated $(P<0.05)$. Significant negative correlations with the sphere and SE were noticed at 6 months for the eyes not requiring enhancements $(P<0.05)$. Flap thickness had no significant relationship to postoperative complications $(P>0.05)$ and no significant predictive value on the rate of enhancement procedures or the efficacy, safety and predictability indices $(P>0.05)$.

Conclusions In myopic LASIK thinner flaps are associated with faster visual recovery and less myopic SE, but the BCVA and the final UCVA are independent of flap thickness. Postoperative complications are unrelated to flap thickness. Flap thickness does not affect the efficacy, safety and predictability, or the rate of enhancement procedures.
H Eleftheriadis, B Prandi, A Diaz-Rato, M Morcillo and JB Sabater

Eye (2005) 19, 1290-1296. doi:10.1038/sj.eye.6701775; published online 24 December 2004

Keywords: LASIK; flap; thickness; myopia; outcome

\section{Introduction}

The advantages of laser in situ keratomileusis (LASIK), ${ }^{1}$ with the fast and almost painless visual recovery have rendered this procedure very popular in the last decade. ${ }^{2}$ In LASIK a corneal flap is created using a microkeratome and an excimer laser ablates the stromal bed. Flap dimensions vary considerably among the various microkeratomes. ${ }^{3-10}$ Although flap diameter variability has not been reported to be a frequently significant problem in myopic laser ablations, flap thickness has been linked to a variety of postoperative complications, such as iatrogenic keratectasia, ${ }^{11,12}$ epithelial ingrowth, ${ }^{13}$ flap dislocation, striae, ${ }^{14}$ and corneal opacities. ${ }^{15-17}$

This study sought to examine the relation of flap thickness to the visual and refractive results of myopic LASIK, in addition to assessing the safety, efficacy, predictability, complication, and enhancement rates in relation to flap thickness.

\section{Materials and methods}

\section{Patient selection}

In this retrospective analysis patients who underwent LASIK for myopia and compound myopic astigmatism in a single treatment centre between December 1999 and January 2001 were studied. Only patients that were 18 years of age or older, with at least 1 year stable refraction, 
spherical equivalent (SE) from -2.00 to -5.00 dioptres (D) at the spectacle plane were eligible for inclusion in this study. All patients were treated with the same excimer laser (Chiron Technolas 217C, Bausch and Lomb) aiming for emmetropia. Patients with a history of ocular disease, previous ocular surgery (including refractive surgery), intraoperative complications, connective tissue disorders or expecting and nursing mothers were also excluded. In order to eliminate the influence of treated optical zone variability on the postoperative results only eyes treated with a $6 \mathrm{~mm}$ optical zone were included in this study. After receiving informed consent all patients underwent a complete ophthalmic assessment that included manifest and cycloplegic subjective refraction, pupillometry, corneal topography, dilated fundoscopy, slit-lamp biomicroscopy, and corneal thickness measurement by contact ultrasound pachymetry (DGH 5100 Pachymeter, DGH Technology Inc, Exton, PA, USA). According to the manufacturer, this model pachymeter is accurate to within $\pm 5 \mu \mathrm{m}$. Central corneal thickness measurements with the DGH have been reported to be accurate, reliable, and reproducible. ${ }^{18}$

\section{Surgical technique}

Topical anaesthesia with oxybuprocaine was instilled in the eye prior to creation of a nasally hinged corneal flap using a manual microkeratome (LSK One, Moria, Antony, France). Microkeratome heads of 100 or $130 \mu \mathrm{m}$ were used according to the desired flap thickness. Intraoperative pachymetry of the central stromal bed (three measurements, considering the mean) was performed following flap elevation and the subtraction method (preoperative minus stromal bed thickness) was used to calculate the flap thickness. All operations were performed by the same experienced surgeon (JBS). After ablation the flap was repositioned on the stromal bed and aligned. Flap alignment and interface were checked immediately at the slitlamp. Interface debris were removed, when necessary, with the help of BSS using a Rycroft cannula mounted in a $5 \mathrm{ml}$ syringe and flap misalignment was corrected similarly at the slitlamp in the theatre area. Postoperatively all patients received topical antibiotic and steroids for 1 week.

\section{Enhancement procedures}

Eyes with stable residual refractive error underwent enhancement procedures, at least 1 month following the initial LASIK surgery. Arcuate keratotomies were performed in eyes with mixed astigmatism, whereas further laser ablation in the stromal bed (Re-LASIK) was performed for all the other residual refractive errors after the initial flap was lifted. All patients had at least 1-month follow-up following retreatment.

\section{Patient examinations}

Postoperative data were collected retrospectively from follow-up visits of day 1, week 1, and months 1 and 6 . For the study of the outcome, parameters such as uncorrected visual acuity (UCVA) (1 day, 1 week, 1 month, 6 months), best spectacle-corrected visual acuity (BCVA) (1 and 6 months), SE (1 and 6 months), presence and type of complications, rate of enhancement procedures required, were studied and their relation to flap thickness were examined. Mean visual acuity was calculated and expressed as the LogMAR equivalent of decimal equivalent as described by Holladay. ${ }^{19}$

\section{Statistical analysis}

For statistical analysis SPSS for Windows version 10.0.7 was used. Measurements of continuous variables were described by their mean, standard deviation, and range. For continuous variables, mean values were compared by the paired or unpaired Student's $t$-test for normally distributed data according to the data under consideration. Differences for nominal variables were tested using the Fisher's exact test for independence. Correlations between flap thickness and continuous variables were determined by linear regression analysis. Logistic regression analysis was used to examine the effect of a $10 \mu \mathrm{m}$ increase in flap thickness on nominal variables. A $P$-value less than 0.05 was considered statistically significant.

\section{Results}

\section{Demographic and preoperative data}

In all, 196 eyes (108 patients) were included in this study. The demographic, preoperative, and operative data are shown in Table 1. In all, 47 eyes (24\%) had flap thickness between 70 and $100 \mu \mathrm{m}, 93(47 \%)$ between 101 and $130 \mu \mathrm{m}$ and 56 (29\%) between 141 and $184 \mu \mathrm{m}$.

\section{Visual and refractive results}

The postoperative visual and refractive results and their relation to flap thickness are displayed in Tables 2 and 3 respectively.

Linear regression analysis revealed a statistically significant negative correlation between flap thickness and UCVA at the first week and the first month but not at 6 months (Table 3). Neither the UCVA of the eyes which underwent retreatment or those that did not show a 
significant correlation to flap thickness at 6 months $(P>0.05)$.

The postoperative sphere was not correlated to flap thickness at 1 month but it was negatively correlated at 6 months. This was mainly due to the eyes that did not require enhancement procedures $(\beta=-0.260, t=-2.875$, $P=0.005)$ and not to the eyes which underwent enhancements $(P=0.695)$, although there was not a significant change $(P>0.05)$ at the sphere between 1 and 6 months in either group of eyes.

A statistically significant negative correlation was found between the SE and flap thickness at 1 but not at 6 months (Table 3 ). However, the SE was negatively correlated to the flap thickness at 6 months $(\beta=-0.202$, $t=-2.203, P=0.030)$ when eyes that underwent enhancement procedures were excluded. There was no significant change in the SE of the eyes that underwent enhancement procedures between 1 and 6 months $(P=0.316)$ as a result of these procedures, or in the eyes that did not required enhancements $(P=0.394)$.

Table 1 Demographic, preoperative, and operative data

Demographic and preoperative data

Number of eyes

Number of patients

Female/male

Age

Sphere

Cylinder

Spherical equivalent

UCVA

BCVA

Pachymetry

Operative data

Flap thickness

Optical zone

Ablation depth

Residual stromal bed

UCVA: uncorrected visual acuity; BCVA: best-corrected visual acuity.

\section{Postoperative complications}

A total of 14 eyes developed postoperative complications. Logistic regression analysis did not reveal any statistically significant relationship between either the total number of complications or to individual postoperative complications and flap thickness $(P>0.05)$. These complications did not result in loss of lines of BCVA more than in uncomplicated eyes at 1 month $(P>0.99)$ and 6 months $(P=0.20)$.

\section{Loss or gain of lines of BCVA}

In all, 3.57 and $2.19 \%$ of eyes lost two or more lines of BCVA at 1 and 6 months, respectively, whereas 89.8 and $90.51 \%$ maintained or gained lines of BCVA at the same times. The flap thickness had no statistically significant predictive value in the number of lines of BCVA lost or gained at $1(P=0.26)$ or 6 months $(P=0.229)$.

Table 3 Table demonstrates the relation of flap thickness to visual and refractive results

\begin{tabular}{lccc}
\hline & \multicolumn{3}{c}{ Flap thickness relation to visual results } \\
\cline { 2 - 4 } & $\beta$ & $t$ & P-value \\
\hline UCVA at 1 day & -0.014 & -0.191 & 0.848 \\
UCVA at 1 week & -0.149 & -2.093 & 0.038 \\
UCVA at 1 month & -0.178 & -2.522 & 0.012 \\
UCVA at 6 months & -0.005 & -0.062 & 0.951 \\
BCVA at 1 month & -0.075 & -1.050 & 0.295 \\
BCVA at 6 months & 0.086 & 1.007 & 0.316 \\
& & & \\
Flap thickness relation to refractive results & & \\
Sphere at 1 month & -0.104 & -1.455 & 0.147 \\
Cylinder at 1 month & -0.088 & -1.232 & 0.22 \\
SE at 1 month & -0.182 & -2.581 & 0.011 \\
Sphere at 6 months & -0.208 & -2.472 & 0.015 \\
Cylinder at 6 months & 0.095 & 1.113 & 0.268 \\
SE at 6 months & -0.155 & -1.827 & 0.070 \\
\hline SE: spherical equivalent; $\beta$ : standardised & regression coefficient; $t: t$ \\
regression coefficient. & & &
\end{tabular}

Table 2 Visual and refractive results

\begin{tabular}{|c|c|c|c|c|}
\hline & Day $1(\mathrm{n}=196)$ & Week $1(\mathrm{n}=196)$ & Month $1(\mathrm{n}=196)$ & Month $6(\mathrm{n}=137)$ \\
\hline UCVA & $0.87 \pm 0.77(0.4-1.5)$ & $0.93 \pm 0.77(0.2-1.5)$ & $0.94 \pm 0.78(0.3-1.5)$ & $0.97 \pm 0.82(0.4-1.5)$ \\
\hline BCVA & & & $1.01 \pm 0.84(0.4-1.5)$ & $1.02 \pm 0.85(0.4-1.5)$ \\
\hline Sphere & & & $-0.03 \pm 0.37 \mathrm{D}(-1.00$ to $+1.50 \mathrm{D})$ & $-0.09 \pm 0.30 \mathrm{D}(-1.00$ to $+0.75 \mathrm{D})$ \\
\hline Cylinder & & & $-0.37 \pm 0.47 \mathrm{D}(-2.50$ to $0 \mathrm{D})$ & $-0.28 \pm 0.31 \mathrm{D}(-1.00$ to $0 \mathrm{D})$ \\
\hline SE & & & $-0.21 \pm 0.32 \mathrm{D}(-1.00$ to 0.88$)$ & $-0.23 \pm 0.30 \mathrm{D}(-1.25$ to +0.50$)$ \\
\hline
\end{tabular}

UCVA: uncorrected visual acuity; BCVA: best-corrected visual acuity; SE: spherical equivalent. 


\section{Enhancement procedures}

Of the eyes, $4.08 \%$ had enhancement by laser and $6.63 \%$ by arcuate keratotomies for residual refractive errors. No eye had retreatment because of regression. Flap thickness did not have any significant effect on the rate of enhancements by laser $(P=0.58)$ or arcuate keratotomies $(P=0.84)$ individually, nor on the rate of enhancements procedures in total $(P=0.60)$. Eyes that underwent enhancement procedures had no significant difference in flap thickness, preoperative sphere, cylinder and SE $(P>0.05)$ from those they did not.

\section{Efficacy, safety, and predictability}

There was no relation of flap thickness to efficacy, predictability, and safety at any time $(P>0.05)$ (Table 4$)$.

\section{Discussion}

The microkeratomes used in LASIK allow surgeons to create flaps with a frequent and well-documented difference between the predicted and the actual thickness. ${ }^{20-25}$ According to manufacturers, flap thickness should ideally fall within $10-15 \%$ of the intended thickness. However, flap thickness shows often a wide variability, ${ }^{3-5,21,22}$ thus intraoperative pachymetry is considered crucial for its measurement.

Flap thickness created by blade-based microkeratomes depends on multiple factors. ${ }^{3-6,15,22,26-34}$ New devices using high-pressure water ${ }^{35}$ and intrastromal lasers ${ }^{36-38}$ have been recently developed to obtain more reproducible corneal flaps and appear to be more consistent than blade-based microkeratomes. ${ }^{39}$

Table 4 Table demonstrates the relation of flap thickness to efficacy, safety, and predictability indices

\begin{tabular}{lccc}
\hline & \multicolumn{3}{c}{$\begin{array}{c}\text { Flap thickness relation to } \\
\text { refractive indices }\end{array}$} \\
\cline { 2 - 4 } & Value (\%) & OR & P-value \\
\hline Efficacy at 1 month & 73.47 & 0.878 & 0.076 \\
Efficacy at 6 months & 74.54 & 0.993 & 0.45 \\
Safety at 1 month & 3.57 & 1.250 & 0.20 \\
Safety at 6 months $_{\text {Predictability (0.5D) }}$ at 1 month & 86.74 & 0.680 & 0.20 \\
Predictability (1D) 1 month & 100 & 0.948 & 0.57 \\
Predictability (0.5D) at 6 months & 87.59 & 0.825 & NA \\
Predictability (1D) at 6 months & 99.27 & 1.878 & 0.292 \\
\hline
\end{tabular}

Efficacy: percentage of eyes with UCVA equal to or greater than preoperative BCVA; Safety: percentage of eyes with a loss of 2 or more Snellen lines of BCVA; Predictability (0.5D): percentage of eyes with spherical equivalent within $\pm 0.5 \mathrm{D}$ from emmetropia; Predictability (1D): percentage of eyes with spherical equivalent within $\pm 1 \mathrm{D}$ from emmetropia.
Although the lamellar flap does not contribute to the biomechanical stability of the cornea in LASIK, it remains a very important factor of this stability as flap thickness determines, along with the ablation depth and the preoperative corneal thickness, the thickness of the RSB. Reduced thickness of the RSB is implicated in the development of iatrogenic keratectasia in normal corneas following LASIK. ${ }^{11,40-43}$ A minimum RSB thickness of $250 \mu \mathrm{m}$ is considered necessary for the prevention of keratectasia. ${ }^{11,44}$

Thicker corneal flaps may result in either excessively reduced stromal bed in cases of very deep lamellar cut ${ }^{12}$ or deeper ablations weakening the biomechanical structure of the cornea, ${ }^{40,45}$ whereas thinner flaps result in more superficial ablations maximising the RSB, thus reducing the risk of keratectasia.

Moreover, the creation of thinner flaps renders more eyes amenable to LASIK. In addition a thicker RSB is of great importance when laser enhancement is contemplated, eliminating the need for another microkeratome pass with the associated potential risks. ${ }^{46}$

It has been suggested by Dr Chayet that thinner flaps may have better UCVA on the first day as they develop less oedema hastening visual recovery (Cheryl Guttman, Ultra-thin flaps may guard against ectasia, Eurotimes, September 2002, pages 1 and 5). We did not notice a significant correlation between UCVA and flap thickness at day 1 . However, a significant negative correlation was observed between flap thickness and UCVA at 1 week and 1 month. We believe that the presence of residual corneal flap oedema at the first postoperative day is responsible for the lack of a significant correlation. Nevertheless gradual resolution of flap oedema by the end of first week reveals the true relation. The reason for the better UCVA in eyes with thinner flaps after the first week is that they simply adopt the shape of the underlying stromal bed better. This may be an advantage in customised ablations over thicker flaps, which mask the fine changes of stromal curvature due to their rigidity. However, the advantage of the thinner flaps in UCVA is lost at 6 months as UCVA improved in eyes with thicker flaps although not significantly $(P>0.05)$, even in the eyes that did not have enhancement procedures. Therefore, one can conclude that eyes with thinner flaps achieve faster visual recovery following myopic LASIK than the thicker ones, but the final UCVA is independent of the flap thickness.

Unlike other investigators, ${ }^{4}$ we found a statistically significant negative correlation between flap thickness and postoperative SE at 1 month, although we did not observe a significant correlation with the postoperative sphere and cylinder individually. Similarly, a significant negative correlation $(P<0.05)$ was observed at 6 months with the SE and the sphere, but not 
the cylinder, for those eyes that did not undergo enhancement procedures.

Thinner flaps have been associated with a higher incidence of complications. ${ }^{13,14,31}$ Epithelial ingrowth has been seen more frequently in eyes with thinner flaps and was attributed to the difficulty in realigning the flap in the stromal bed. ${ }^{13}$ Excessive manipulation under the flap to obtain proper alignment may result in implantation of loose epithelial cells in the interface and epithelial ingrowth. We believe that our technique of checking and realigning the flap, and, if necessary, cleaning the interface from debris and obvious epithelial cells, at the slitlamp are the main reasons for the low incidence of epithelial ingrowth in our cohort $(0.51 \%)$.

It has also been suggested that thinner flaps may be displaced easier than thicker ones and may result in striae. ${ }^{14}$ Excessive manipulations may lead to flap oedema, which in turn reduces the adherence of the flap and increases the risk of flap displacement and striae. In our study, we have observed a very low incidence of flap striae $(0.51 \%)$ even though almost a quarter of the flaps were thinner than $100 \mu \mathrm{m}$.

A number of confocal microscopy studies in myopic human eyes following LASIK have shown a negative correlation between flap thickness and subclinical haze, ${ }^{47}$ and activated - cell area thickness. ${ }^{47,48}$ Other confocal microscopy studies have confirmed the development of clinical haze in eyes with thin flaps but flap thickness is not the only aetiologic factor, as it does not happen exclusively in eyes with thin flaps. ${ }^{16}$ Thinner flaps affect the integrity of the most anterior keratocyte layer that, through release of several cytokines from the corneal epithelium ${ }^{49}$ may control the keratocyte activation, myofibroblast transformation and haze formation after lamellar refractive surgery. ${ }^{48}$

Central corneal opacities in eyes with very thin flaps have been described, ${ }^{15-17}$ attributed mainly to ablation of the Bowman's layer. We have not observed corneal opacities in any of our patients despite $24 \%$ of the eyes in our study had flaps between 70 and $100 \mu \mathrm{m}$. We believe that the reason for this is that we did not violate the Bowman's layer. Although the term 'thin flap' has been used extensively in the literature, it appears that there is not a consensus of opinion regarding its definition. One should distinguish between pathologically thin flaps where there is dissection within the Bowman's layer, or even the epithelium (ie buttonholes), which may eventually lead to the creation of corneal scarring, and reduced thickness flaps with the lamellar cut below the Bowman's. Lamellar flaps thinner than $60 \mu \mathrm{m}$ are suspicious as average corneal epithelium are approximately $50 \mu \mathrm{m}^{50}$ and Bowman's layer $10 \mu \mathrm{m}$. Appropriate measures to avoid pathologically thin flaps have been described. ${ }^{14}$
The enhancement rate in our cohort $(10.71 \%)$ is within the range (5.5-36\%) published in large series. ${ }^{51,52}$ Logistic regression analysis revealed that increasing flap thickness had no significant effect on the rate of enhancement procedures.

Ambrosio and Wilson ${ }^{31}$ have suggested that thin flaps may be associated with regression caused by epithelial hyperplasia due to the proximity of the epithelium to stromal wound healing response and epithelium modulating growth factor production. We did not observe a significant regression between 1 and 6 months in our group for the eyes which did not require enhancement procedures $(P>0.05)$.

The limitations of our study are the short follow-up and the relatively small number of patients. As complications after LASIK are rare, a large number of patients are required in order to determine whether there is a relationship between flap thickness and individual postoperative complications. In addition, intraoperative ultrasound pachymetry for the measurement of flap thickness by the subtraction method is subject to errors due to overhydration and dehydration of the cornea. ${ }^{53,54}$

In conclusion, in myopic LASIK thinner flaps are associated with faster visual recovery although the BCVA and the final UCVA are independent of flap thickness. In addition flap thickness is inversely related to SE, with eyes with thinner flaps achieving less myopic SE refraction. Postoperative complications are not related to flap thickness, provided that the lamellar cut and laser ablation respect the Bowman's layer. Moreover, enhancement rate, efficacy, safety, and predictability are not influenced by flap thickness.

\section{References}

1 Pallikaris IG, Papatzanaki ME, Siganos DS, Tsilimbaris MK. A corneal flap technique for laser in situ keratomileusis. Human studies. Arch Ophthalmol 1991; 109: 1699-1702.

2 Leaming DV. Practice styles and preferences of ASCRS members-2002 survey. J Cataract Refract Surg 2003; 29: 1412-1420.

3 Ucakhan OO. Corneal flap thickness in laser in situ keratomileusis using the summit Krumeich-Barraquer microkeratome. J Cataract Refract Surg 2002; 28: 798-804.

4 Yi WM, Joo CK. Corneal flap thickness in laser in situ keratomileusis using an SCMD manual microkeratome. J Cataract Refract Surg 1999; 25: 1087-1092.

5 Yildirim R, Aras C, Ozdamar A, Bahcecioglu H, Ozkan S. Reproducibility of corneal flap thickness in laser in situ keratomileusis using the Hansatome microkeratome. J Cataract Refract Surg 2000; 26: 1729-1732.

6 Gailitis RP, Lagzdins M. Factors that affect corneal flap thickness with the Hansatome microkeratome. J Refract Surg 2002; 18: 439-443.

7 Arbelaez MC. Nidek MK 2000 microkeratome clinical evaluation. J Refract Surg 2002; 18: S357-S360. 
8 Srivannaboon S. Flap analysis: critical point in laser in situ keratomileusis. J Med Assoc Thai 2001; 84: 1317-1320.

9 Jacobs BJ, Deutsch TA, Rubenstein JB. Reproducibility of corneal flap thickness in LASIK. Ophthalmic Surg Lasers 1999; 30: 350-353.

10 Shemesh G, Dotan G, Lipshitz I. Predictability of corneal flap thickness in laser in situ keratomileusis using three different microkeratomes. J Refract Surg 2002; 18: S347-S351.

11 Seiler T, Koufala K, Richter G. Iatrogenic keratectasia after laser in situ keratomileusis. J Refract Surg 1998; 14: 312-317.

12 Haw WW, Manche EE. Iatrogenic keratectasia after a deep primary keratotomy during laser in situ keratomileusis. Am J Ophthalmol 2001; 132: 920-921.

13 Asano-Kato N, Toda I, Hori-Komai Y, Takano Y, Tsubota K. Epithelial ingrowth after laser in situ keratomileusis: clinical features and possible mechanisms. Am J Ophthalmol 2002; 134: 801-807.

14 Melki SA, Azar DT. LASIK complications: etiology, management, and prevention. Surv Ophthalmol 2001; 46: 95-116.

15 Pallikaris IG, Katsanevaki VJ, Panagopoulou SI. Laser in situ keratomileusis intraoperative complications using one type of microkeratome. Ophthalmology 2002; 109: 57-63.

16 Buhren J, Kohnen T. Stromal haze after laser in situ keratomileusis: clinical and confocal microscopy findings. J Cataract Refract Surg 2003; 29: 1718-1726.

17 Yeo HE, Song BJ. Clinical feature of unintended thin corneal flap in LASIK: 1-year follow-up. Korean J Ophthalmol 2002; 16: 63-69.

18 Wheeler NC, Morantes CM, Kristensen RM, Pettit TH, Lee DA. Reliability coefficients of three corneal pachymeters. Am J Ophthalmol 1992; 113: 645-651.

19 Holladay JT. Proper method for calculating average visual acuity. J Refract Surg 1997; 13: 388-391.

20 Behrens A, Seitz B, Langenbucher A, Kus MM, Rummelt C, Kuchle M. Evaluation of corneal flap dimensions and cut quality using a manually guided microkeratome. J Refract Surg 1999; 15: 118-123.

21 Behrens A, Seitz B, Langenbucher A, Kus MM, Rummelt C, Kuchle M. Evaluation of corneal flap dimensions and cut quality using the Automated Corneal Shaper microkeratome. J Refract Surg 2000; 16: 83-89.

22 Durairaj VD, Balentine J, Kouyoumdjian G, Tooze JA, Young $\mathrm{D}$, Spivack L et al. The predictability of corneal flap thickness and tissue laser ablation in laser in situ keratomileusis. Ophthalmology 2000; 107: 2140-2143.

23 Maldonado MJ, Ruiz-Oblitas L, Munuera JM, Aliseda D, Garcia-Layana A, Moreno-Montanes J. Optical coherence tomography evaluation of the corneal cap and stromal bed features after laser in situ keratomileusis for high myopia and astigmatism. Ophthalmology 2000; 107: 81-87.

24 Spadea L, Cerrone L, Necozione S, Balestrazzi E. Flap measurements with the Hansatome microkeratome. J Refract Surg 2002; 18: 149-154.

25 Perez-Santonja JJ, Bellot J, Claramonte P, Ismail MM, Alio JL. Laser in situ keratomileusis to correct high myopia. J Cataract Refract Surg 1997; 23: 372-385.

26 Binder PS, Moore M, Lambert RW, Seagrist DM. Comparison of two microkeratome systems. J Refract Surg 1997; 13: 142-153.

27 Gimbel HV, Penno EE, van Westenbrugge JA, Ferensowicz $\mathrm{M}$, Furlong MT. Incidence and management of intraoperative and early postoperative complications in
1000 consecutive laser in situ keratomileusis cases. Ophthalmology 1998; 105: 1839-1847.

28 Kim YH, Choi JS, Chun HJ, Joo CK. Effect of resection velocity and suction ring on corneal flap formation in laser in situ keratomileusis. J Cataract Refract Surg 1999; 25: 1448-1455.

29 Liu KY, Lam DS. Direct measurement of microkeratome gap width by electron microscopy. J Cataract Refract Surg 2001; 27: 924-927.

30 Kasetsuwan N, Pangilinan RT, Moreira LL, DiMartino DS, Shah SS, Schallhorn SC et al. Real time intraocular pressure and lamellar corneal flap thickness in keratomileusis. Cornea 2001; 20: 41-44.

31 Ambrosio Jr R, Wilson SE. Complications of laser in situ keratomileusis: etiology, prevention, and treatment. J Refract Surg 2001; 17: 350-379.

32 Davidorf JM, Zaldivar R, Oscherow S. Results and complications of laser in situ keratomileusis by experienced surgeons. J Refract Surg 1998; 14: 114-122.

33 Seo KY, Wan XH, Jang JW, Lee JB, Kim MJ, Kim EK. Effect of microkeratome suction duration on corneal flap thickness and incision angle. J Refract Surg 2002; 18: 715-719.

34 Leung AT, Rao SK, Cheng AC, Yu EW, Fan DS, Lam DS Pathogenesis and management of laser in situ keratomileusis flap buttonhole. J Cataract Refract Surg 2000; 26: 358-362.

35 Lipshitz I, Bass R, Loewenstein A. Cutting the cornea with a waterjet keratome. J Refract Surg 1996; 12: 184-186.

36 Ito M, Quantock AJ, Malhan S, Schanzlin DJ, Krueger RR. Picosecond laser in situ keratomileusis with a 1053-nm Nd:YLF laser. J Refract Surg 1996; 12: 721-728.

37 Ratkay-Traub I, Juhasz T, Horvath C, Suarez C, Kiss K, Ferincz I et al. Ultra-short pulse (femtosecond) laser surgery: initial use in LASIK flap creation. Ophthalmol Clin North Am 2001; 14: 347-355.

38 Nordan LT, Slade SG, Baker RN, Suarez C, Juhasz T, Kurtz $\mathrm{R}$. Femtosecond laser flap creation for laser in situ keratomileusis: six-month follow-up of initial US clinical series. J Refract Surg 2003; 19: 8-14.

39 Kezirian GM, Stonecipher KG. Comparison of the IntraLase femtosecond laser and mechanical keratomes for laser in situ keratomileusis. J Cataract Refract Surg 2004; 30: 804-811.

40 Spadea L, Palmieri G, Mosca L, Fasciani R, Balestrazzi E. Iatrogenic keratectasia following laser in situ keratomileusis. J Refract Surg 2002; 18: 475-480.

41 Amoils SP, Deist MB, Gous P, Amoils PM. Iatrogenic keratectasia after laser in situ keratomileusis for less than -4.0 to -7.0 diopters of myopia. J Cataract Refract Surg 2000; 26: 967-977.

42 Argento C, Cosentino MJ, Tytiun A, Rapetti G, Zarate J. Corneal ectasia after laser in situ keratomileusis. J Cataract Refract Surg 2001; 27: 1440-1448.

43 Pallikaris IG, Kymionis GD, Astyrakakis NI. Corneal ectasia induced by laser in situ keratomileusis. J Cataract Refract Surg 2001; 27: 1796-1802.

44 Wang Z, Chen J, Yang B. Posterior corneal surface topographic changes after laser in situ keratomileusis are related to residual corneal bed thickness. Ophthalmology 1999; 106: 406-409.

45 Joo CK, Kim TG. Corneal perforation during laser in situ keratomileusis. J Cataract Refract Surg 1999; 25: 1165-1167.

46 Tekwani NH, Chalita MR, Krueger RR. Secondary microkeratome-induced flap interference with the pathway of the primary flap. Ophthalmology 2003; 110: 1379-1383. 
47 Pisella PJ, Auzerie O, Bokobza Y, Debbasch C, Baudouin C. Evaluation of corneal stromal changes in vivo after laser in situ keratomileusis with confocal microscopy. Ophthalmology 2001; 108: 1744-1750.

48 Vesaluoma M, Perez-Santonja J, Petroll WM, Linna T, Alio J, Tervo T. Corneal stromal changes induced by myopic LASIK. Invest Ophthalmol Vis Sci 2000; 41: 369-376.

49 Li DQ, Tseng SC. Differential regulation of cytokine and receptor transcript expression in human corneal and limbal fibroblasts by epidermal growth factor, transforming growth factor-alpha, platelet-derived growth factor B, and interleukin-1 beta. Invest Ophthalmol Vis Sci 1996; 37: 2068-2080.

50 Reinstein DZ, Silverman RH, Rondeau MJ, Coleman DJ. Epithelial and corneal thickness measurements by high-frequency ultrasound digital signal processing. Ophthalmology 1994; 101: 140-146.

51 Zadok D, Maskaleris G, Garcia V, Shah S, Montes M, Chayet A. Outcomes of retreatment after laser in situ keratomileusis. Ophthalmology 1999; 106: 2391-2394.

52 Stulting RD, Carr JD, Thompson KP, Waring III GO, Wiley WM, Walker JG. Complications of laser in situ keratomileusis for the correction of myopia. Ophthalmology 1999; 106: 13-20.

53 Maldonado MJ, Juberias JR, Rodriguez-Conde R. Corneal flap thickness and tissue laser ablation in myopic LASIK. Ophthalmology 2002; 109: 1042-1043.

54 Lam DS, Rao SK, Liu KY. Microkeratome accuracy in LASIK. Ophthalmology 2001; 108: 1930-1932. 